\title{
PENGENDALIAN LEVEL CAIRAN TANGKI DENGAN MENGGUNAKAN SIMULASI FUZZY BERBASIS MATLAB
}

\section{The Control Of Liquid Tank Level Using Fuzzy Simulation By Matlab}

\author{
Apip Pudin \\ Jurusan Teknik Konversi Energi, Politeknik Negeri Bandung \\ email: apip055@yahoo.com
}

\begin{abstract}
Abstrak
Tangki sebagai suatu penyimpan cairan sangat banyak digunakan untuk berbagai keperluan baik sektor industri maupun sektor publik dan komersial. Pengendalian level tangki telah banyak dilakukan baik secara analog maupun digital. Demikian juga, berbagai metode pengontrolan banyak digunakan pada sistem otomatisasi industri. Metode Fuzzy merupakan salah satu metode yang berhasil digunakan dalam pengendalian tingkat cairan (liquid level) pada suatu sistem tangki. Pengendalian berbasis fuzzy logic direpresentasikan dengan simulasi Matlab dengan menggunakan Fuzzy Sugeno, yaitu metode pada studi kasus sistem tangki tunggal [6]. Metode ini bertujuan untuk melihat interaksi parameter sinyal output seperti waktu respon, error, waktu pengendapan dan melampui batas, serta hasil yang dibandingkan dengan performa terbaik dari pengendali PID pada sistem. Hasil simulasi menunjukkan bahwa sinyal keluaran kendali fuzzy dapat menghilangkan overshoot secara signifikan dengan settling time 5 detik untuk error $1 \%$.
\end{abstract}

Kata kunci: fuzzy control, level, error, error change, Sugeno method

\begin{abstract}
Tank as liquid storage has many usage in industrial, public and commercial sector. The control of tank level are used either in analog or digital system. It also used in industrial automation systems. Fuzzy method is one of the successful methods applied to control the liquid level in the tank system. Methods on the case study of the single tank system was shown in a Matlab simulation with the Fuzzy Sugeno [6]. This method were conducted to see the interaction of signal output parameters such as response time, error, settling time, and overshoot and then the results compared with the best performance of PID controller on the same system. The result showed that output signal by fuzzy control reduced the overshoot significantly with 5 seconds of settling time for $1 \%$ error.
\end{abstract}

Keywords: fuzzy control, level, error, error change, Sugeno method

\section{PENDAHULUAN}

Sistem otomatis pada pengisian atau pembuangan cairan dalam suatu tangki merupakan proses yang secara luas banyak digunakan di industri khususnya industri kimia karena berhubungan dengan banyak process plant yang karakteristiknya tergantung pada 
perubahan level cairan seperti air, minyak dan cairan kimia lainnya.

Proses pengisian dan pembuangan cairan dalam tangki yang tertutup menyulitkan bagi operator mengetahui apakah level cairan dalam tangki tersebut melebihi atau kurang dari batas yang dinginkan, atau laju aliran masuk menjadi tidak sebanding dengan laju aliran keluar. Sistem otomatisasi diperlukan untuk mengendalikan level cairan agar senantiasa berada pada level yang diinginkan.

Simulasi kontrol fuzzy dengan menggunakan metode Fuzzy Sugeno. Sinyal kontrol diperoleh dari perbedaan antara keluaran yang diharapkan (set point) dengan keluaran sebenarnya (level) yang disebut kesalahan (error) yang kemudian diproses menggunakan logika fuzzy. Keluaran sistem dari metode Sugeno berupa konstanta-konstanta berbeda yang merepresentasikan bukaan valve.

Simulasi selanjutnya dilakukan menggunakan Simulink dan Fuzzy Logic Toolbox pada program Matlab.

\section{METODOLOGI}

Sistem tangki yang akan disimulasikan seperti pada Gambar 1 dan sistem pengendaliannya memenuhi proses nonself regulating dimana persamaan untuk mencari level ketinggian dalam tangki ditentukan dengan persamaan $[3,5]$,

$$
h=\frac{Q}{A} \int\left(f_{i}-f_{o}\right) d t
$$

dengan $h$ adalah ouput proses, $f_{i}-f_{o}$ sebagai input error dan $\frac{Q}{A}$ disebut time constant $(\tau)$.

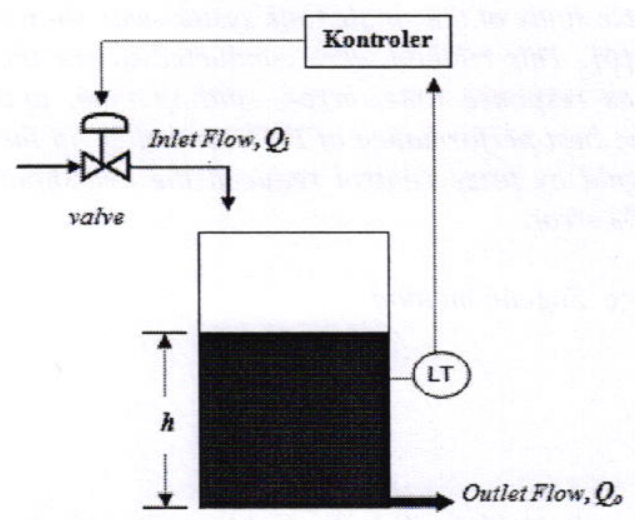

Gambar 1. Diagram Skema Pengontrolan Level Cairan dalam Tangki
Sistem terdiri dari katup air (valve), tangki, sensor level, dan kontroler (FLC). Air diasumsikan dipompa mengalir secara konstan sebelum debitnya diatur oleh controlled valve mengalir masuk tangki. Ketinggian air dalam tangki dideteksi oleh suatu sensor level dan dikonversi kedalam sinyal yang dapat diterima oleh kontroler. Setelah itu kontroler membandingkan sinyal level terukur dengan nilai level yang dikehendaki atau set point. Dari sini dapat diperoleh nilai kesalahan (error) dan perubahan kesalahan (derror) yang menjadi input dari pengontrol fuzzy (FLC). Error dihitung dengan mengambil perbedaan antara sinyal referensi dan ketinggian (level) cairan yang sedang berjalan, sedangkan perubahan error dihitung dengan pengurangan error sebelumnya dari error yang sedang berjalan. Output dari FLC adalah berupa tegangan yang digunakan untuk mengatur kecepatan bukaan dan penutupan valve sehingga laju aliran masuk akan mengkompensasi laju aliran keluar. Jadi untuk mengendalikan level cairan dalam tangki bisa dengan cara mengatur bukaan valve yang konfigurasinya sesuai dengan basis aturan fuzzy Sugeno.

Sistem pengendalian digambarkan dengan diagram blok (Gambar 2).

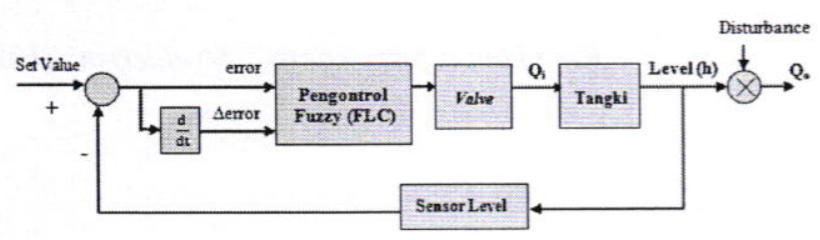

\section{Gambar 2. Sistem Loop Tertutup dengan Kontrol Fuzzy}

Penentuan fungsi keanggotaan dan basis aturan dilakukan melalui perancangan fungsi keanggotaan dari masing-masing input (error dan perubahan error) dan output (bukaan valve) menggunakan aplikasi Fuzzy Toolbox pada perangkat lunak Matlab. Fungsi keanggotaan error dipetakan dalam tiga variabel linguistik yaitu Negatif, Nol, dan Positif, dengan nilai data tegas (crisp) antara 1 dan 1. Fungsi keanggotaan perubahan error (disimbolkan dengan derror) juga dipetakan dalam tiga variabel linguistik yaitu Negatif, Nol, dan Positif dengan data tegas antara -0.1 dan 0.1 . 
Perancangan fungsi keanggotaan output sinyal kontrol berupa output singleton dengan jangkauan antara -1 dan 1 yang dipetakan dalam lima kelas variabel linguistik ${ }^{[4]}$. Kelima variabel tersebut adalah Tutup Cepat dengan nilai singleton -0.9 , Tutup Pelan dengan nilai 0.5 , Tetap dengan nilai 0 , Buka Pelan dengan nilai 0.5, dan Buka Cepat dengan nilai 0.9.

Penyusunan aturan-aturan fuzzy ditampilkan dalam Tabel 1 berikut.

Tabel 1 .Matriks Keputusan Rancangan Aturan Logika Fuzzy

\begin{tabular}{|c|c|c|c|}
\hline $\begin{array}{c}\text { Error } \\
\text { dError }\end{array}$ & Negatif & Nol & Positif \\
\hline Negatif & $\begin{array}{l}\text { Tutup } \\
\text { Cepat }\end{array}$ & $\begin{array}{l}\text { Tutup } \\
\text { Pelan }\end{array}$ & $\begin{array}{l}\text { Buka } \\
\text { Cepat }\end{array}$ \\
\hline Nol & $\begin{array}{l}\text { Tutup } \\
\text { Cepat }\end{array}$ & Tetap & $\begin{array}{l}\text { Buka } \\
\text { Cepat }\end{array}$ \\
\hline Positif & $\begin{array}{l}\text { Tutup } \\
\text { Cepat }\end{array}$ & $\begin{array}{l}\text { Buka } \\
\text { Pelan }\end{array}$ & $\begin{array}{l}\text { Buka } \\
\text { Cepat }\end{array}$ \\
\hline
\end{tabular}

Tiap-tiap aturan yang telah dirancang dieksekusi dengan menggunakan metode pengambilan keputusan Sugeno dan nilai keluaran yang yang diperoleh di-defuzzifikasi menjadi nilai keluaran crisp dengan metode rata-rata berbobot (weighted average).

Deskripsi aturan di atas diaplikasikan menggunakan tool FIS Editor pada Fuzzy Toolbox pada Matlab ${ }^{[6]}$ sebagai berikut:

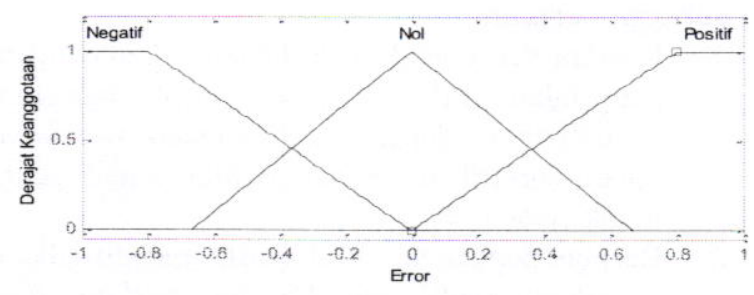

Gambar 3. Kurva Fungsi Keanggotaan "Error"

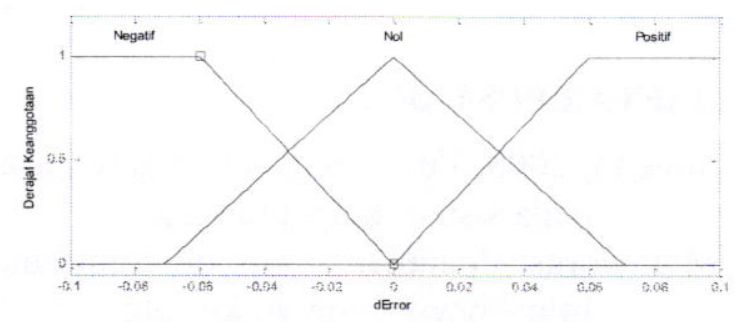

Gambar 4. Kurva Fungsi Keanggotaan "Perubahan Error"

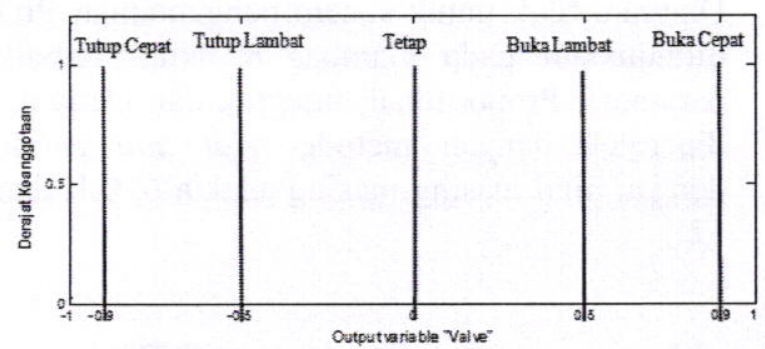

\section{Gambar 5. Kurva Fungsi Keanggotaan Keluaran "Valve"}

\section{HASIL DAN PEMBAHASAN}

Diagram blok Simulink untuk simulasi sistem tangki ditunjukkan seperti pada Gambar 6 . Model tangki berbentuk silinder dengan tinggi 2 meter dan luas alas (area) $1 \mathrm{~m}^{2}$, luas penampang outlet (outlet area) $0,05 \mathrm{~m}^{2}$ serta ketinggian awal level cairan dalam tangki diseting $0,5 \mathrm{~m}$ [2]. Blok untuk volume tangki "tank volume" adalah suatu integrator dengan integrasi terbatas antara 0 dan tinggi area tangki. Blok untuk valve adalah suatu fungsi integrasi satuan antara nilai 0 (yang menyatakan valve dalam keadaan tertutup) dan 1 (valve dalam keadaan terbuka).

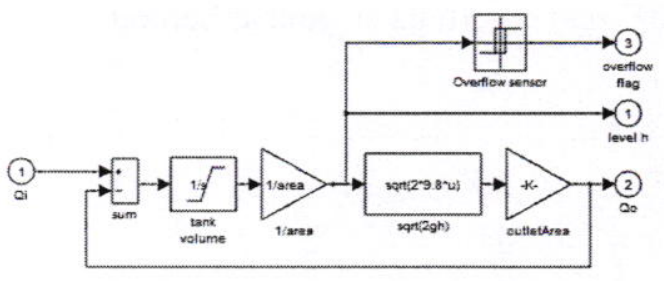

\section{Gambar 6. Model Simulink Sistem Tangki}

Akhirnya diagram blok Simulink untuk sistem pengendalian fuzzy ditunjukkan sebagai berikut (Gambar 7).

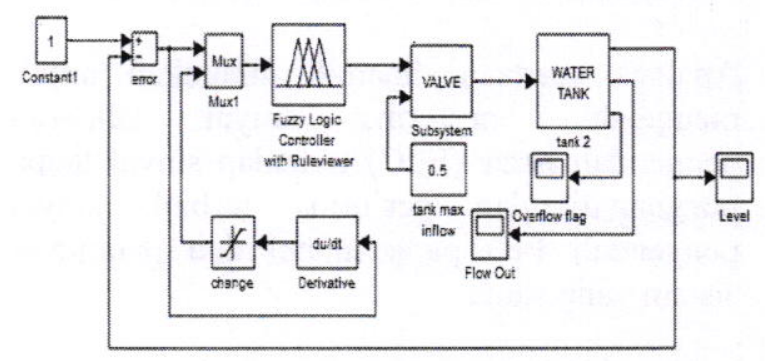

Gambar 7. Model Simulink Pengendalian Fuzzy 
Diagram blok untuk sistem pengendalian PID ditunjukkan pada Gambar 8. Nilai terbaik parameter Proportional, Integral, dan Derivatif diperoleh dengan metode trial and error, dengan nilai masing-masing adalah $6,0.1$, dan 12.

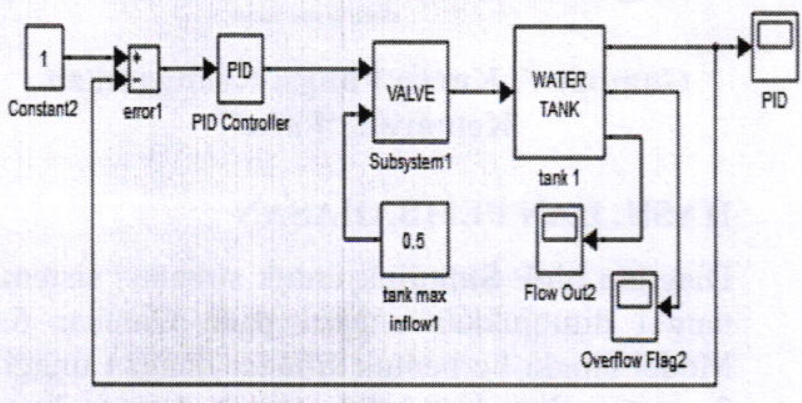

\section{Gambar 8. Model Simulink Pengendalian PID}

Simulasi keadaan dinamik sistem dilakukan pada rentang waktu $\mathrm{t}=0$ sampai $\mathrm{t}=10$ detik. Kondisi ini dengan mengasumsikan kecepatan pengisian tidak memperhitungkan volume tangki. Sinyal keluaran pengendali Fuzzy dalam bentuk posisi bukaan valve yang merupakan fungsi error dan perubahan error (dError) seperti pada gambar berikut,

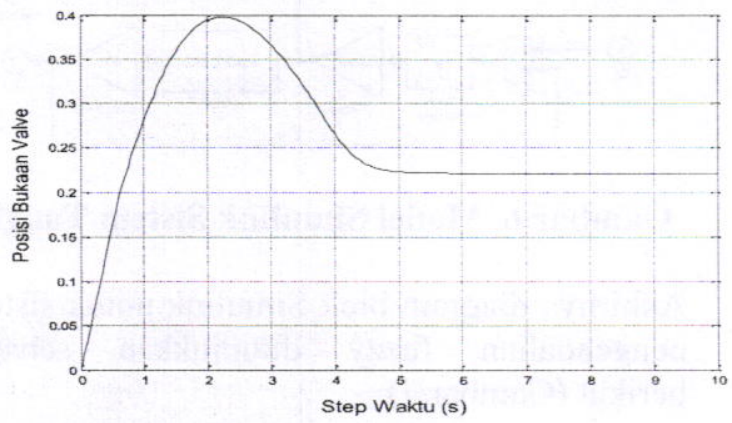

Gambar 9. Kurva Posisi Bukaan Valve

Analisis keadaan dinamik dilakukan untuk mengetahui performa sinyal keluaran pengendali fuzzy (FLC) terhadap sinyal tanpa pengendali dan performa terbaik sinyal pengendali PID pada model dan parameter sistem yang sama.

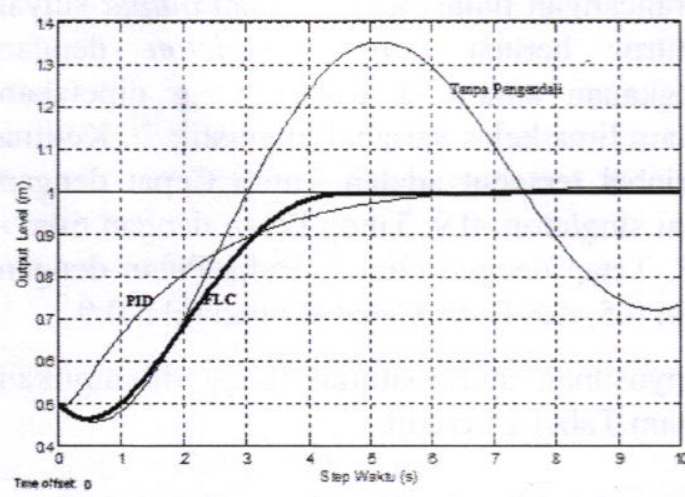

Gambar 10. Kurva Respon Output FLC, Pengendali PID, dan Tanpa Pengendali

Gambar 10 menunjukkan respon keluaran pengendali Fuzzy (FLC) yang dibandingkan dengan respon kendali PID. Hasil simulasi menunjukkan bahwa kendali fuzzy lebih baik dibandingkan dengan pengendali PID, dimana sinyal keluaran kendali fuzzy dapat menghilangkan overshoot secara signifikan dengan settling time 5 detik untuk error $1 \%$. Sedangkan respon pengendali PID masih menghasilkan overshoot maksimum 4\% dan settling time lebih lama sebesar 6.5 detik pada nilai error yang sama. Namun demikian pengendali PID lebih baik dalam menghilangkan waktu delay respon output.

\section{KESIMPULAN}

Hasil simulasi menunjukkan beberapa hal sebagai berikut :

1. Kendali fuzzy lebih baik dibandingkan dengan pengendali PID, dimana sinyal keluaran kendali fuzzy dapat menghilangkan overshoot secara signifikan dengan settling time 5 detik untuk error $1 \%$.

2. Respon pengendali PID masih menghasilkan overshoot maksimum $4 \%$ dan settling time lebih lama sebesar 6.5 detik pada nilai error yang sama.

\section{DAFTAR PUSTAKA}

Sugeno, 2003, Fuzzy Sugeno : Studi kasus pada sistem tangki tunggal.

Mathworks' documentations on Simulink, http://www.mathworks.com

P.Berk, D.Stanjnko, P.Vindis, B. Mursec, M. Lakota, "Synthesis Water Level Control by Fuzzy Logic", Journal of Achiefments in Materials and 
Manufacturing Engineering, Zulaikah, Wahyudi, Trias Andromeda, Volume 45, April 2011.

Timothy J.Ross, "Fuzzy Logic With Engineering Application", Jonh Wiley \& Sons, 2010.

Jack golten, Andy Verwer, "Control system Design and Simulation", McGraw-Hill, 1991 "Aplikasi Teknik Kendali Fuzzy Pada Pengendalian Level Cairan”, Makalah Seminar Tugas Akhir, Jurusan Teknik Elektro, Universitas Diponegoro, - 